Zaret del Rosario Luévano Estrada 


\section{¿Cómo se entiende la obra de arte y lo bello en la Modernidad?}

\section{Introducción}

Para este trabajo lo que queremos hacer es un análisis general del arte, así como de sus implicaciones en lo social y en quienes trabajan el aspecto artístico, además de cuestionarnos qué es el arte y qué posibles efectos represente en el público que lo consume o lo adquiere; nuestro escrito no contiene un aparato crítico como tal, sino lo que más bien hacemos es una reflexión en torno a los pormenores señalados, aclarando que las fuentes que se presentan al final del escrito, son de referencia y las mismas que se emplearon para elaborar y dar luz a esta reflexión.

\section{La obra de arte y lo bello}

Imaginémonos como un inventor que, tratando de evadir el tedio, casi por entretención, creamos un artefacto, de éste cuelga en movimiento de vaivén un objeto ¿su utilidad? No importa, lo creamos únicamente por distracción, para observarlo. Tiempo después, siendo el mismo inventor, pero más viejo, nos encontramos frente a una multitud mostrándoles un invento revolucionario, el reloj. Solo nosotros sabemos que, sin la primera creación, la del péndulo, no hubiéramos llegado al reloj. Podríamos pensar al péndulo como un reloj muy raquítico, o al reloj como un péndulo muy sofisticado, pero el hecho es que, aunque tengan una familiaridad, una innegable herencia, no son lo mismo, el primero nunca se pensó como un instrumento para medir el tiempo y el segundo no fue creado al azar.

Pasa algo muy parecido con las obras de arte, les llamamos así a objetos que de origen probablemente no lo son, estas son un objeto exclusivo de la modernidad y las 
épocas posteriores a esta. Como si las obras de arte fueran nuestro reloj y algunos otros objetos, los objetos bellos, nuestro péndulo. En la modernidad aparece, como resultado de discusiones muy complejas e incompletas, y como una pieza clave para el desarrollo del tema, el concepto de arte, al que responden las obras de arte, su sentido y su justificación.

Identificar las diferencias que existen entre uno objeto bello y una obra de arte, así como de lo bello premoderno a lo bello en la modernidad, es aclarar una relación enigmática entre lo pasado con lo nuevo. Pretendo pues, exponer algunas de las desigualdades para con ello volver más claro que era lo que los modernos entendían por obras de arte y la belleza.

Hay algunos aspectos claves que distinguen, hacen más precisa, la distinción entre estas clases de objetos, las obras de arte de los objetos bellos:

- la finalidad objeto o el objetivo del artista al crearlo.

Es bien sabido que los artistas medievales sentían una indiferencia por el reconocimiento popular, las obras de estos pretendían únicamente hacer una representación de los iconos religiosos con la finalidad, tal vez, de simular el parecido entre lo divino y lo humano, como si tener la escultura de un dios, un santo o un ángel fuera suficiente para convencerse que, de hecho, esta frente a un dios, un santo o un ángel. Siendo esta su finalidad aspectos estilísticos, colores, formas, armonía, espacio, etc., quedaban a un lado en muchas ocasiones pues su objetivo era representar y la belleza en estas obras dependía de aquello que simbolizaban.

En cambio, el artista moderno tiene como objetivo, de manera consciente o inconsciente, atender tanto al aspecto sensorial como al de la sensibilidad. Aparecen objetos que son creados, única y exclusivamente, para causar algo en los sentidos del sujeto y con ello en él, crear una experiencia totalmente nueva y 
sensible, dice Baumgarten, que además se pueda pensar. ¿cómo pensar la relación de las obras de arte, con la recepción que tiene el sujeto de estas y con su contemplación? Surge la ciencia del conocimiento sensible o como popularmente se le conoce estética, como una disciplina no que estudia al arte, sino que estudia la relación entre los sentidos del sujeto, el sujeto y el objeto.

Es complicado intentar demarcar una línea entre el origen del arte y el arte como es concebido en la modernidad, tratar incluso de definir arte siempre lleva a una discusión que se torna circular, complicada y ambigua pero que gracias a conceptos y figuras que surgen en la modernidad, como estética, artista, público, gusto, imaginación, etc. Se puede dar la investigación en estas áreas, sino de manera más fácil, más clara.

Para la modernidad se establecen, no de manera formal, aspectos pronunciados y más objetivos en torno a objetos, que los convierten en obra de arte.

a) Las obras de arte son creadas por un artista. Aunque esta afirmación parece particularmente obvia, es necesario mencionarla pues a diferencia de las obras de épocas pasadas, con excepción de algunos grandes nombres, los creadores, autores, escultores, pintores no representaban un papel importante en la obra. El trabajo era reconocido pero el artista permanecía en el anonimato, cuando en la modernidad surgen las obras de arte estas a su vez demandan un autor que puede o no obtener cosas de ellas como fama, reconocimiento, haciéndose, la del artista, una profesión, con suerte, cotizada. El hecho de que alguien puede dedicarse todo el tiempo y paciencia, a la única tarea de estudiar y crear objeto artístico transforma el valor de la profesión del artista. Se vuelve un oficio en el que un sujeto es capaz de, con sus obras, provocar en otras sensaciones placenteras, desagradables, etc. en otro.

b) El arte, es arte en relación al sujeto; la figura del sujeto que contempla, sin la ambición de encontrar un símbolo religioso, una obra era también nueva en la 
modernidad, cuando los objetos dejan de atender más a una representación y procuran cosas como belleza, adquieren una popularidad entre la sociedad, la gente acude a las obras de arte para experimentar el gozo o cualquier otra sensación que les cause, aparece un público que observa, que consume, que demanda obras de arte, y si bien al principio era un grupo pequeño $y$ perteneciente a una exclusiva clase social con el tiempo se amplía tanto el gusto como el público, pues no todos disfrutan de lo mismo.

c) Al estar una obra disponible a un público capaz incluso la mínima opinión, como expresar el agrado o desagrado, el gozo o la aberración, surge en la sociedad moderna del arte aquellos quienes se dedicarán a opinar y reflexionar de una manera más objetiva, algunas veces, los cambios, las características, las experiencias, el artista, el concepto, formas, colores, etc. en torno al arte.

Pareciera entonces que cualquiera, y cualesquiera cosas, podrían ser una obra de arte, la pregunta escandalosa generada con lo anterior es ¿Quién es entonces quien decide cuando un objeto es una obra de arte y cuando no: el artista, el público, el sujeto o el crítico? La discusión fue atendida por dos representantes de la época y es en torno a como de hecho identificamos los objetos artísticos: subjetiva o objetivamente. Exponentes dominantes en la época hablan de esto:

Los románticos quienes creían que la determinación del arte era una cuestión subjetiva, percibían al sujeto moderno como un ente carente de intuición sensible la cual solo se satisfacía por los objetos artísticos y la experiencia estética.

Kant otro representante del pensamiento moderno afirma que el arte no se determina de manera subjetiva aunque si es por algo perteneciente al sujeto, es la capacidad universal, pues parece poseen todos los sujetos, de crear juicios, solamente que los juicio acerca del arte, o como él los llama juicios del gusto son distintos a otro tipo 
de juicios pues estos determinan, mediante datos que nos proporciona los objetos, que posteriormente gracias a la capacidad de entendimiento separamos en lo que llama categorías y que por último la imaginación se encarga de ordenar, el gusto de cada individuo que es distinto entre si pues el juego entre estas tres capacidades es distinto en cada sujeto. Entonces, aunque pareciera que es el sujeto quien decide que es arte, que es bello o no, en realidad su decisión solo es una proyección de un juego en el que se encuentran los sentidos, la imaginación y el entendimiento.

La belleza también es un término -o una cualidad- que se transforma con la llegada del arte, los objetos bellos eran el centro de atención de los amantes de lo sensible, cuando llega el arte y la estética demostrando que puede generarse un placer, a cosas que no parecen ser bellas, cosas pintorescas o grotescas etc., la belleza baja del altar en el que parece haber estado durante siglos y se reúne con estas otras categorías, llama Kant, que también ofrecen al sujeto una experiencia estética

\section{Conclusión}

En todas las épocas, y civilizaciones la presencia de cosas como la música, la pintura, la escritura es primordial para un desarrollo social pues fomenta aspectos, por ejemplo, de cooperatividad, de identidad, pero más que por el hecho de promover una supervivencia parece que es una necesidad innata del hombre. La edad moderna creo yo, es una etapa en la que no solo se comienza a hablar, discutir y con ello entender el arte y aspectos de este como, la estética, la belleza, el placer, sino que es el pilar de una disciplina, o barias, que estudiaran un pensamiento y un quehacer fundamental en el hombre, el de hacer arte. 


\section{Fuentes de referencia}

Bozal, Valeriano. (2000) Historia de las ideas estéticas y las teorías artísticas contemporáneas. España: Visor.

Cassin, Barbara (Dir.) Labastida, Jaime (coord.). (2018). Vocabulario de las filosofias occidentales. CDMX: Siglo XXI.

Kant, Immanuel. (I987) Primera introducción a la crítica del juicio. España: Visor.

Kant, Immanuel. (2003) Observaciones sobre el sentimiento de lo bello y lo sublime. Mexico:FCE. UAM. UNAM.

Safranski, Rudiger. (2012) Romanticismo, una odisea del espíritu alemán. (Gabás, Raúl.). España: Tusquets. 